Research Article

\title{
Genetic variability in the Skyros pony and its relationship with other Greek and foreign horse breeds
}

\author{
Elisabeth Bömcke ${ }^{1,2, *}$, Nicolas Gengler ${ }^{1,3}$ and E. Gus Cothran ${ }^{4}$ \\ ${ }^{1}$ Animal Science Unit, Gembloux Agricultural University, Gembloux, Belgium. \\ ${ }^{2}$ F.R.I.A., Brussels, Belgium. \\ ${ }^{3}$ National Fund for Scientific Research, Brussels, Belgium. \\ ${ }^{4}$ Animal Genetics Lab., VIBS, CVM, Texas A\&M University, College Station, Texas, USA.
}

\begin{abstract}
In Greece, seven native horse breeds have been identified so far. Among these, the Skyros pony is outstanding through having a distinct phenotype. In the present study, the aim was to assess genetic diversity in this breed, by using different types of genetic loci and available genealogical information. Its relationships with the other Greek, as well as foreign, domestic breeds were also investigated. Through microsatellite and pedigree analysis it appeared that the Skyros presented a similar level of genetic diversity to the other European breeds. Nevertheless, comparisons between DNA-based and pedigree-based results revealed that a loss of genetic diversity had probably already occurred before the beginning of breed registration. Tests indicated the possible existence of a recent bottleneck in two of the three main herds of Skyros pony. Nonetheless, relatively high levels of heterozygosity and Polymorphism Information Content indicated sufficient residual genetic variability, probably useful in planning future strategies for breed conservation. Three other Greek breeds were also analyzed. A comparison of these with domestic breeds elsewhere, revealed the closest relationships to be with the Middle Eastern types, whereas the Skyros itself remained isolated, without any close relationship, whatsoever.
\end{abstract}

Key words: genetic variation, genetic markers, pedigree, horse.

Received: December 21, 2009; Accepted: November 26, 2010.

\section{Introduction}

Today and worldwide, the populations of numerous domestic animals, especially horses, are in steady decline, with some already extinct, thereby affecting both interbreed (decline in the actual number of equine breeds themselves) and intra-breed (decline in the number of individuals) diversities. This, for example, is the case in Greece, where, according to the statistics of the Food and Agriculture Organisation (FAO), over the past twenty years the horse population has decreased by over $60 \%$.

Recently, arrays of DNA based markers have been developed, both to undertake studies of genetic variability, and to investigate genetic relationships between populations (Bradley et al., 1996; Cañon et al., 2000; Solis et al., 2005). Among these, microsatellites are considered by many to be the most suitable marker system for evaluating breed genetic diversity (Takezaki and Nei, 1996). Several genetic studies of equine populations have described the

Send correspondence to E. Gus Cothran. Animal Genetics Lab., VIBS, CVM, Texas A\&M University, TAMU 4458, College Station, TX 77843-4458, USA. E-mail: gcothran @ cvm.tamu.edu.

'Present address: Gembloux Agricultural University, Animal Science Unit, Gembloux, Belgium. usefulness of microsatellite markers, as well as blood group and biochemical loci, for establishing genetic relationships between populations, and for describing genetic variability among and within breeds (Cothran et al., 1998; Cañon et al., 2000; Aranguren-Mendez et al., 2002; Juras et al., 2003; Aberle et al., 2004; Gupta et al., 2005; GlowatzkiMullis et al., 2005; Luis et al., 2007; Royo et al., 2007). Nowadays, however, these are being progressively replaced by SNP markers, in, for example, the control of relationships (e.g. IBD matrix) (Flury et al., 2010). Nevertheless, in small breeds, genotyping with high density SNP chips turns out to be very expensive, thereby limiting the availability of such data.

Historically, Greece has had a profound influence on the development of Western civilization. However, little is known, not only as to the relationships of Greek domestic animals to other foreign breeds, but also to their own origins and breeding histories. Greece, due to its geographic location, is a crossroad between three continents. Furthermore, its mountainous terrain and numerous islands have lead to the creation of many small populations of distinct and isolated breeds. On the basis of phenotypes and genotypes, seven native horse breeds have been identified so far 
(Zafrakas, 1991; Alifakiotis, 2000), namely the Crete, the Elis Mountain (or Pinias), the Elis Valley (or Andravidas), the Skyros, the Thessalias, the Pindos and the Zakynthos. The names attributed to these breeds are those of the various regions where they were originally preponderant (Alifakiotis, 2000). Among these, the phenotype in the Skyros pony is distinct from those of the other breeds (Zafrakas, 1991). This in itself is a small-sized animal, with an average adult height of $109 \mathrm{~cm}$ in stallions and $107 \mathrm{~cm}$ in mares. They are mainly bay-colored with dark and strong hooves, and very long manes and tails (Alifakiotis, 2000). As shown by Apostolidis et al. (2001), this phenotypic difference seems to be linked to the Skyros pony being genetically less similar to the other Greek horse breeds than these themselves to one another. However, the literature is very poor concerning the description of Greek horse breeds in general. The Skyros pony population, in particular, has never been studied in its entirety, as neither have the genetic relationships of Greek horse breeds as a whole, either mutually or with other domestic breeds elsewhere.

Population sizes in the Greek breeds are estimated to range from 50 to over 1000 individuals (Alifakiotis, 2000; DAD-IS 2007). Thus, most can be considered as small, and, according to criteria established by the FAO (FAO, 1998; DAD-IS, 2007), in a critical- or endangered-maintained risk status. Genetic principles, when applied to a small population, indicate that the genetic variability of such a population will decrease across generations, with the consequential need for increased conservation measures. Genetic variability may be defined as the 'genetic ability to change', and therefore, the capacity to respond to environmental variation and future needs (Rochambeau et al., 2000). Thus, the evaluation of genetic variability is one of the first steps in the process of species genetic conservation, in accordance with the hypothesis of correlations between preserving both genetic variability and population viability. The analysis of the information contained in registered pedigrees can also contribute towards knowledge on population structure and the evaluation of genetic variability (Valera et al., 2005).

In this study, four of these native Greek horse breeds, viz., the Crete and Pinias horses, and the Skyros and Pindos ponies, were studied, with a special focus on the most distinct of the four, the Skyros pony, for which genetic markers and pedigree data were available. The Skyros pony is mainly found on the island of Skyros, situated in the Aegean Sea. Two reasons led to discerning the risk status of this genetically original breed as critical-maintained (DAD-IS, 2007), according to criteria established by the Food and Agriculture Organization (FAO, 1998), the first being the reduced population size (about 200 individuals), and the second, that this population, through being concentrated in three main herds (Skyros, Corfu and Thessaloniki), is vulnerable to demographic accidents. Initially the aim was to quantify genetic variability in the breed it- self, to thereafter compare the levels of genetic variability among all the four horse breeds studied and estimate mutual genetic distances, and then extend the comparison to other domestic horse breeds, as a way towards a better understanding of how the horses of Greece fit into the diversity of domestic horses as a whole.

\section{Materials and Methods}

\section{Population samples}

A total of 211 horses from the four Greek horse breeds chosen (see Table 4) were sampled and tested for genetic variation at seven blood-group, ten biochemical genetic and 12 microsatellite loci, using standard techniques (Sandberg and Cothran, 2000; Juras and Cothran, 2004). Although sample size for the Pindos pony was only 15 individuals, due the rarity of the breed, this represented about $10 \%$ of the total population. In all, 99 Skyros ponies (37 males and 62 females), coming from the three main related sub-populations, were tested for genetic variation at 16 microsatellite loci by using DNA extracted from hair samples (Vogelstein and Gillespie, 1979). This represents approximately $58 \%$ of the entire population of living animals considered as belonging to the Skyros pony breed.

The two Skyros pony data sets could not be combined because samplings were done independently. Due to the lack of pedigree information, it was impossible to relate animals from the first sampling to those from the second, although it is probable that some animals were included in both. With more or the same number of markers in both sets, it would have been possible to control the relationships, with, for example, either a IBD matrix based on SNP data (VanRaden, 2008), or a combined relationship matrix of Bömcke and Gengler (2009).

\section{Marker characterization}

The 17 horse blood-groups and biochemical loci examined in the 211 samples of Greek horse breeds were $T F$, $A 1 B, E S, A L B, G C, P G D, P G M, G P I, H B A, P I, H B G A$, $H B G C, H B G D, H B G K, H B G P, H B G Q$ and $H B G U$, and the 12 microsatellite loci VHL20, HTG4, AHT4, HMS7, HTG6, AHT5, HMS6, ASB2, HTG10, HTG7, HMS3 and HMS2.

For the 99 Skyros ponies, the 16 microsatellite loci included the above 12, plus ASB23, ASB17, HMS1 and $C A 425$. Polymerase chain reaction (PCR) and microsatellite genotyping were according to the StockMarks ${ }^{\circledR}$ Horse protocol. Results for HTG10 could not be scored in this sampling.

\section{Statistical analysis of genotyping data}

Gene frequencies for biochemical loci and microsatellite loci were calculated by direct counting. Allele frequencies at blood-group loci were calculated by the allocation method (Andersson, 1985). The inter-breed genetic 
variation measures calculated were observed heterozygosity $(\mathrm{Ho})$ and Hardy-Weinberg expected heterozygosity (He; Nei, 1987), the effective number of alleles (Ae, i.e. the inverse of the probability that two randomly taken genes represent the same allele), the total number of alleles (TNA), the mean number of alleles per locus (MNA), and the deviation in $\mathrm{He}$ from Ho (Fis; Caballero and Toro, 2002). Ho was not calculated for blood group loci due to the presence of recessive alleles and/or ambiguous genotypes at blood group loci. Therefore, for direct comparison, $\mathrm{He}$ was calculated only for biochemical or microsatellite loci. Genetic distances among the four breeds were calculated by Nei's modified genetic distance (Da). The resemblance to other domestic breeds, as well as Greek-breed interrelationships, were summarized in a dendrogram using the Restricted Maximum Likelihood method (REML from PHYLIP; Felsenstein, 1993). Dendrograms, calculated by employing SEQBOOT, CONTML and CONSENSE routines in the PHYLIP program, and drawn using TreeView (Page, 1996), were based upon 1000 bootstraped REML runs. Data, for both breed variability means and the dendrograms of breed relationships, were obtained from samples collected by EGC for an ongoing study of genetic diversity in domestic horses (see Juras et al., 2003; Luis et al., 2007).

Genetic diversity within Skyros populations was measured with the same above-mentioned measures, plus Polymorphism Information Content (PIC) and HardyWeinberg Equilibrium (HWE) and p-value (HW-P). Most parameters were computed using Microsatellite Analyser (MSA) (Dieringer and Schlötterer, 2002). HWE tests were carried out with 'GENEPOP on the web' (Raymond and Rousset, 1995). Exact HW-Ps were calculated, along with their standard deviations, using the Guo and Thompson (1992) Markov-Chain algorithm, with 1,000 de-memorization steps for every 400 batches and 1,000 iterations per batch. The BOTTLENECK programme (Cornuet and Luikart, 1996) was employed for detecting any possible bottleneck when using various statistical tests, viz., the sign and standardized differences tests (Cornuet and Luikart, 1996; Luikart and Cornuet, 1998). As recommended by Luikart and Cornuet (1998) and Piry et al. (1999), the two-phase mutation model (TPM) was used, with $70 \%$ of the stepwise mutation model (SMM; Ohta and Kimura, 1973) and 30\% of the infinite allele model (IAM; Kimura and Crow, 1964).

\section{Pedigree analysis}

The Skyros pony preliminary studbook was only very recently established, and thus contains only 395 animals, namely those born between 1958 and 2006. Based on these limited data, the pedigree completeness level was characterized by computing various parameters, such as:

1. The average generation interval, defined as the average age of parents at the birth of their descendants. This average was computed for the period of the last 15 years and four pathways (father-son/-daughter, motherson/-daughter).

2. The percent of known ancestors per parental generation.

3. The number of generation-equivalents (geq), often considered the best criterion for characterizing pedigree information. This was computed as the sum of $(1 / 2)^{n}$, where $n$ is the number of generations separating the individual from each known ancestor (Maignel et al., 1996).

Additionally, in order to characterize genetic variability within the Skyros pony population, the following parameters were analyzed:

1. The effective number of founders $\left(\mathrm{f}_{\mathrm{e}}\right)$, i.e., the number of equally contributing founders that would be expected to produce the same level of genetic diversity as in the population under study (Lacy, 1989). A founder is defined as an ancestor with unknown parents (Boichard et al., 1997). $\mathrm{f}_{\mathrm{e}}$ is a measure of how the balance in founder contributions is maintained across generations. The more balanced the contributions of the founders, the higher $\mathrm{f}_{\mathrm{e}}$. It accounts for the selection rate and variation in family size (Maignel et al., 1996).

2. The effective number of ancestors $\left(f_{a}\right)$, i.e. the minimum number of ancestors required to construe the complete genetic diversity of the studied population (Boichard et al., 1997), as an account of the losses in genetic variability produced, not only by the unbalanced use of reproductive individuals, but also by detected bottlenecks in the pedigree (Maignel et al., 1996).

3. The effective number of founder genomes $\left(\mathrm{N}_{\mathrm{g}}\right)$, i.e. the number of equally contributing founders, with no random loss of founder alleles in the offspring, and with the expectancy of producing the same genetic diversity as in the population under study (MacCluer et al., 1986; Chevalet and de Rochambeau, 1986; Lacy, 1989). This is a measure of how many founder genes have been maintained in the population for a given locus and how stable their frequency (Maignel et al., 1996).

Parameters 2 and 3 were studied only for the living population (represented by the animals born between 1992 and 2006).

Most of the parameters were computed using the PEDIG package developed by Boichard (2002).

\section{Results}

\section{The Skyros pony: Intra-breed diversity}

Most of the animals (77\%) in the Skyros pony preliminary studbook were registered after 1989. The number of births has been on a global decline since 1998 (except in the years 2001 and 2004) (data not shown). Figure 1 characterizes the completeness level of the studbook. For the first parental generation, pedigree completeness was only about $75 \%$, dropping to about $40 \%$ in the $2^{\text {nd }}$ and to less than $5 \%$ after the $3^{\text {rd }}$. As parentages have only recently been regu- 


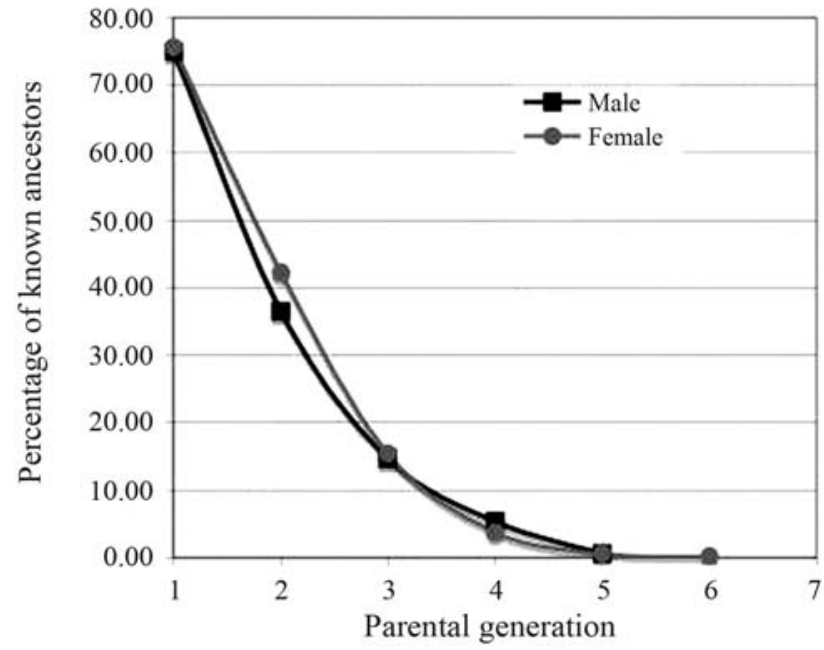

Figure 1 - The completeness level of the Skyros small-horse studbook assessed by means (over the last 10 years) by percentage of known ancestors per parental generation, with parental generation 1 corresponding to parents, 2 corresponding to grandparents, etc.

larly recorded, and as the average generation interval is relatively high for an endangered breed (9.18 years, Table 1), and, furthermore, even considering this value as being consistent with the biology and behaviour of equines as a whole, the number of geq was calculated according to the individual year of birth (Figure 2). This number increased regularly and reached values of 1.88 for females in 2006 . The most relevant information on the concentration and origin of genomes in the Skyros small-horse breed appears in Table 1. $\mathrm{f}_{\mathrm{e}}$ was equal to 13.30 animals, $\mathrm{f}_{\mathrm{a}}$ to 13.08 and $\mathrm{N}_{\mathrm{g}}$ to 10.30. Even though the number of ancestors explaining $99.82 \%$ of genetic variability was 60 , only 5 individuals were necessary to explain $50 \%$ and 10 to explain $70 \%$.

The results from DNA analysis of 15 microsatellite loci in the 99 Skyros ponies studied appears in Table 2. A total of 89 different alleles were detected across these 15 loci. TNA per locus in the complete population ranged

Table 1 - Genealogical parameters characterizing the probabilities of gene origin in the Skyros pony breed.

\begin{tabular}{lc}
\hline Total number of recorded animals & 395 \\
Average generation interval (over the last 15 years and & 9.18 \\
the four pathways) & \\
$\quad$ Father-son & 9.98 \\
Father-daughter & 8.96 \\
Mother-son & 8.85 \\
$\quad$ Mother-daughter & 8.91 \\
Animals with unknown parents & 104.0 \\
Effective number of founder animals & 13.3 \\
Effective number of ancestors & 13.1 \\
Effective number of founder genomes & 10.3 \\
Number of ancestors explaining $70 \%$ & 10 \\
Number of ancestors explaining $50 \%$ & 5 \\
\hline
\end{tabular}

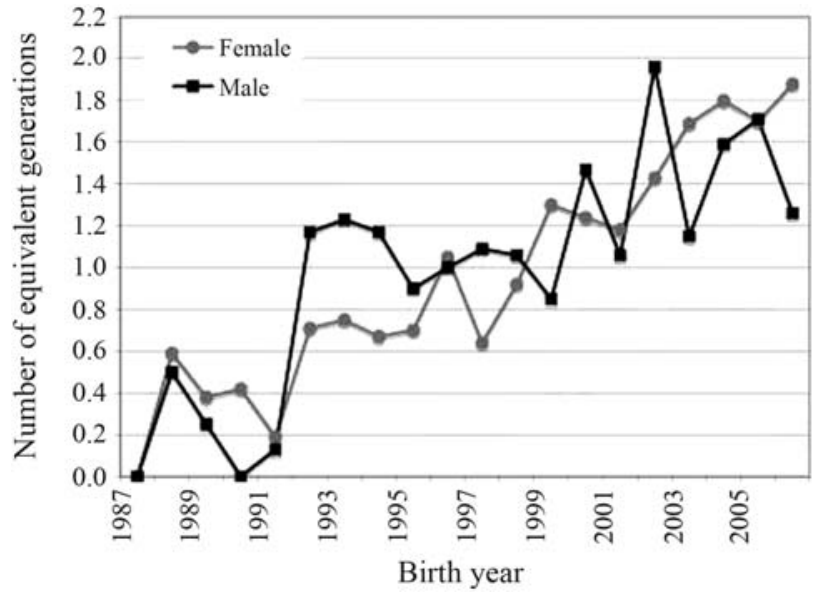

Figure 2 - Average number of equivalent generations, according to the year of birth and sex of the population.

from 4 to 10, with an $M N A$ of 5.93. The average $A e$ was 3.22. No significant $(\mathrm{HW}-\mathrm{P}<0.01)$ deviation from HWE was found. In most cases, the loci were highly polymorphic, thus implying heterozygosity was moderate to high $(H o>0.5)$. The average $H o$ over all loci in the Skyros population was 0.647 . This was similar to values obtained in the second part of the study, although there were certain differences between individual loci and loci in common. The average $\mathrm{He}$ was 0.621 . Although the average $\mathrm{Ho}$ and $\mathrm{He}$ did

Table 2 - Molecular parameters describing genetic variability in the Skyros pony population.

\begin{tabular}{|c|c|c|c|c|c|c|}
\hline \multicolumn{3}{|c|}{$\begin{array}{l}\text { Number of genotyped } \\
\text { individuals }\end{array}$} & \multicolumn{4}{|c|}{99} \\
\hline Locus & TNA & $\mathrm{Ae}$ & HW-P & Но & $\mathrm{He}$ & PIC \\
\hline VHL20 & 6.000 & 3.969 & 0.285 & 0.697 & 0.750 & 0.724 \\
\hline HTG4 & 4.000 & 1.205 & 0.273 & 0.172 & 0.170 & 0.166 \\
\hline AHT4 & 5.000 & 2.651 & 0.820 & 0.586 & 0.624 & 0.585 \\
\hline$H M S 7$ & 7.000 & 4.641 & 0.739 & 0.768 & 0.786 & 0.767 \\
\hline HTG6 & 5.000 & 1.928 & 0.757 & 0.444 & 0.482 & 0.451 \\
\hline AHT5 & 6.000 & 3.726 & 0.961 & 0.707 & 0.733 & 0.712 \\
\hline HMS6 & 6.000 & 1.905 & 0.688 & $0.535 *$ & 0.476 & 0.443 \\
\hline$A S B 23$ & 6.000 & 4.069 & 0.721 & $0.808 *$ & 0.756 & 0.734 \\
\hline$A S B 2$ & 6.000 & 3.823 & 0.802 & $0.788 *$ & 0.740 & 0.716 \\
\hline$H T G 7$ & 4.000 & 2.622 & 0.164 & $0.697 *$ & 0.620 & 0.585 \\
\hline$H M S 3$ & 7.000 & 3.155 & 0.119 & $0.831 *$ & 0.686 & 0.666 \\
\hline$H M S 2$ & 5.000 & 3.489 & 0.365 & $0.808 *$ & 0.715 & 0.691 \\
\hline$A S B 17$ & 10.000 & 6.806 & 0.371 & 0.838 & 0.855 & 0.842 \\
\hline HMS1 & 5.000 & 1.355 & 0.961 & $0.283 *$ & 0.263 & 0.254 \\
\hline CA425 & 7.000 & 2.962 & 0.973 & $0.737 *$ & 0.664 & 0.639 \\
\hline Average & 5.933 & 3.220 & 0.884 & 0.647 & 0.621 & 0.598 \\
\hline
\end{tabular}

TNA $=$ total number of alleles, $\mathrm{Ae}=$ effective number of alleles, HW$\mathrm{P}=$ Hardy-Weinberg Equilibrium $\mathrm{p}$-value, $\mathrm{Ho}=$ observed heterozygosity, $\mathrm{He}=$ expected heterozygosity, $\mathrm{PIC}=$ Polymorphism Information Content. *Significant heterozygosity excess. 
not differ significantly in 8 loci, $H o$ was significantly higher than $\mathrm{He}$, possibly indicating a genetic bottleneck in the population. Table 3 presents the results of the two tests carried out to detect this possible bottleneck (sign test and standardized differences test). As none was detected in the complete population, testing was extended to each subpopulation. Test results indicated significant heterozygosity excess in two herds, the Thessaloniki and Corfu. The average PIC for the 15 microsatellites was 0.598 . From PIC values it was inferred that 11 of the 15 markers were highly informative (PIC > 0.5) in terms of their suitability for genetic diversity studies, whereas the remaining four were less so (Table 2).

\section{The relationship between theSkyros pony and other Greek horse breeds}

The alleles observed at the 29 loci examined, as well as their frequencies, are available on request. No allele unique to any of the Greek breeds was observed. Unique or uncommon alleles have been observed on a regular, though infrequent, basis at blood group and biochemical loci (for example, see Cothran and Long, 1994), but are not common for microsatellites, due to the nature of the variation. Genetic variability measures are given in Table 4.

Genetic associations among the breeds, as given in Table 5, show that these are not so closely related to each other as might be expected by geographic distances, although the Pindos and Pinias are believed to be so (Figure 3). The Crete Horse is closest to the Pindos and Pinias, whereas the Skyros revealed no close relationship to any of the Greek breeds examined.

Due to the large number of breeds for comparison, the consensus tree is based on 1000 bootstrapped REML runs according to blood group and biochemical loci (Figure 3). Trees, based only upon microsatellite, as well as combined protein and microsatellite data, were also produced, but, through being substantially the same, are not shown.

\section{Discussion}

Genetic variability in the Skyros pony breed was investigated, using both pedigree and microsatellite information. Results based on pedigree analysis showed that the parameters computed for this breed were quite similar to those computed for other European horse breeds.

Table 3 - Results of Sign tests and Standardized differences tests for heterozygosity excess in 15 microsatellite locus from Skyros pony populations under TPM.

\begin{tabular}{lcccccc}
\hline \multirow{2}{*}{ Populations } & \multirow{2}{*}{ No. of individuals sampled } & \multicolumn{2}{c}{ Sign test } & & \multicolumn{2}{c}{ Standardized differences tests } \\
\cline { 3 - 4 } \cline { 6 - 7 } & & $\mathrm{H}_{\text {excess }} / \mathrm{h}_{\text {deficit }}$ & $\mathrm{P}$ & & $\mathrm{T}_{2}$ & $\mathrm{p}$ \\
\hline Skyros & 50 & $10 / 5$ & 0.376 & & 0.416 & 0.339 \\
Thessaloniki & 24 & $11 / 2$ & $0.039^{* *}$ & & 2.288 & $0.011^{* *}$ \\
Corfu & 25 & $12 / 3$ & $0.050^{* *}$ & & 2.188 & $0.014^{* *}$ \\
Global & 99 & $9 / 6$ & 0.582 & & 0.724 & 0.234 \\
\hline
\end{tabular}

$\mathrm{H}_{\text {excess }}=$ number of loci with heterozygosity excess. $\mathrm{H}_{\text {deficit }}=$ number of loci with heterozygosity deficit. ** Significant heterozygosity excess.

Table 4 - Measures of genetic variation in 4 Greek horse breeds by blood group and biochemical loci (upper row), and by microsatellite loci (bottom row, in bold). For blood group and biochemical loci, $\mathrm{Ho}, \mathrm{He}$, and $\mathrm{Fis}$ were calculated from biochemical loci only. The other measures were from both types of loci. For the microsatellite loci, all loci were used in the calculation of each measure.

\begin{tabular}{lccccccc}
\hline Breed & $n$ & $H o$ & $H e$ & $F i s$ & $A e$ & $T N A$ & $M N A$ \\
\hline CH & 40 & 0.335 & 0.349 & 0.038 & 2.284 & 70 & 4.12 \\
& $\mathbf{3 0}$ & $\mathbf{0 . 7 1 5}$ & $\mathbf{0 . 7 4 3}$ & $\mathbf{0 . 0 3 8}$ & $\mathbf{4 . 1 8 2}$ & $\mathbf{9 0}$ & $\mathbf{7 . 5 0}$ \\
PS & 30 & 0.307 & 0.344 & 0.109 & 2.385 & 66 & 3.88 \\
& $\mathbf{2 9}$ & $\mathbf{0 . 7 1 3}$ & $\mathbf{0 . 7 5 3}$ & $\mathbf{0 . 0 5 3}$ & $\mathbf{4 . 3 3 1}$ & $\mathbf{8 2}$ & $\mathbf{6 . 8 3}$ \\
SK & 126 & 0.434 & 0.418 & -0.025 & 2.335 & 68 & 4.00 \\
& $\mathbf{4 7}$ & $\mathbf{0 . 6 4 4}$ & $\mathbf{0 . 6 4 1}$ & $\mathbf{- 0 . 0 0 5}$ & $\mathbf{3 . 1 5 1}$ & $\mathbf{6 9}$ & $\mathbf{5 . 7 5}$ \\
PP & 15 & 0.353 & 0.345 & -0.023 & 2.484 & 63 & 3.71 \\
& $\mathbf{1 5}$ & $\mathbf{0 . 7 9 4}$ & $\mathbf{0 . 7 4 5}$ & $\mathbf{- 0 . 0 6 6}$ & $\mathbf{4 . 2 6 3}$ & $\mathbf{7 7}$ & $\mathbf{6 . 4 2}$ \\
Domestic horse mean & 114 & 0.371 & 0.365 & -0.051 & 2.343 & 65.1 & 3.83 \\
& $\mathbf{4 2}$ & $\mathbf{0 . 6 8 4}$ & $\mathbf{0 . 6 6 7}$ & $\mathbf{- 0 . 0 2 9}$ & $\mathbf{3 . 4 9 8}$ & $\mathbf{6 7 . 3}$ & $\mathbf{5 . 6 1}$ \\
\hline
\end{tabular}

Crete Horse (CH), Pinias (PS), Skyros Pony (SK), Pindos Pony (PP), $n$ values for the Domestic mean are the number of breeds tested; $H o=$ observed heterozygosity, $\mathrm{He}=$ expected heterozygosity, Fis = deviation in $\mathrm{He}$ from $\mathrm{Ho}, \mathrm{Ae}=$ effective number of alleles, $T N A=$ total number of alleles, $M N A=$ mean number of alleles per locus. 


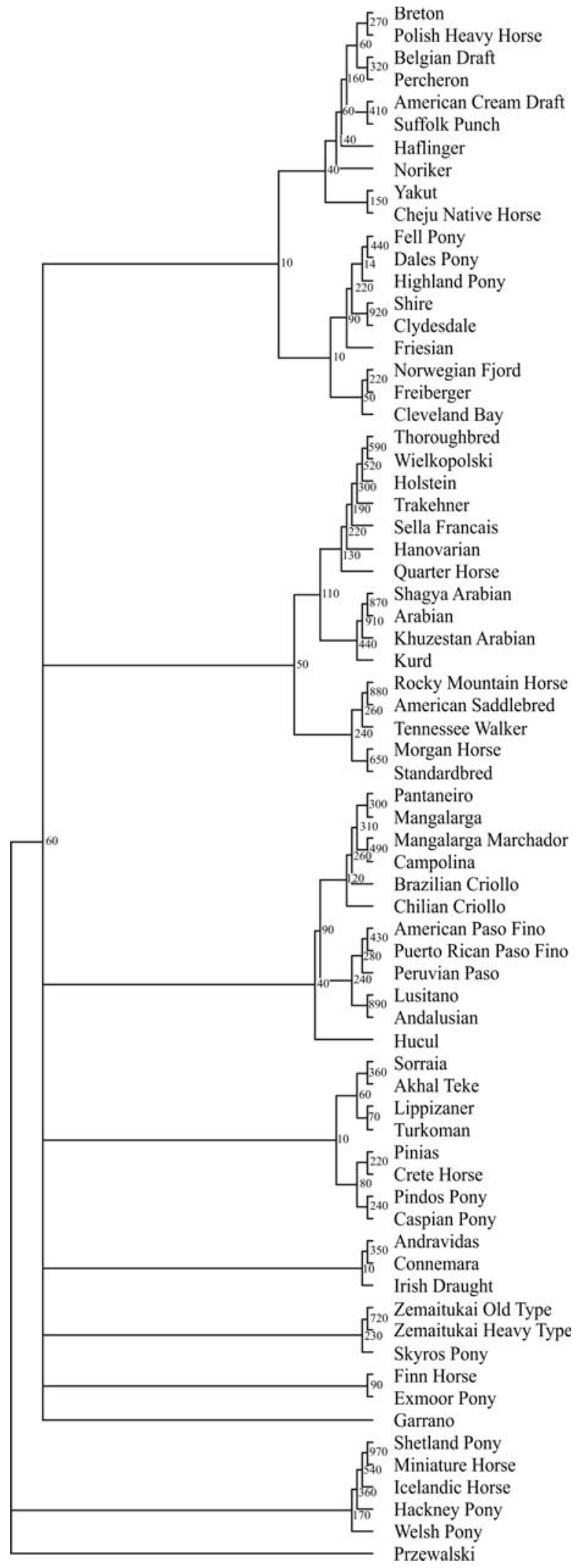

Figure 3 - REML dendrogram of Chord distance (Cavalli-Sforza and Edwards, 1967) among the four Greek breeds and 64 other breeds, based upon 17 blood group and biochemical genetic loci (bootstrap values based upon 1000 replicates are at the nodes). The Przewalski horse was used as outgroup.
In comparison to other studbooks, the Skyros pony preliminary studbook proved to be much less complete. It is characterized by a very high percentage of animals with one or both parents unknown $(26.33 \%$ and $35.45 \%$ as against $1.94 \%$ and $1.28 \%$ for the Andalusian studbook) (Valera et al., 2005). This situation is explained by long generation intervals, births having only recently been recorded, and mares roaming free, to return pregnant, the sire being obviously unknown. In comparison, the percentage of known ancestors in the Lipizzan studbook, for example, was above $90 \%$ at the $10^{\text {th }}$ generation and above $70 \%$ at the $14^{\text {th }}$ (Curik et al., 2003). This value is comparable to the first generation in the Skyros studbook, although the situation is improving, with the value of geq globally increasing according to the birth-year of the animals. Generation intervals computed for the Skyros breed were lower than those reported for other horse breeds with deeper pedigrees, as the 9.7 years in French Arabs and 11.8 in Trotteur Français (Moureaux et al., 1996). Even so, this is very high for an endangered breed. Generation intervals in horses are commonly long (Strom and Philipsson, 1978), this basically depending on its use (leisure or racing) being incompatible with pregnancy and a breeding life. For the Skyros pony, the cause is more linked to management, with 60 ancestors being accountable for about $100 \%$ of genetic variability. This value was lower than the 331 reported for Andalusian horses (Valera et al., 2005). Although the values for the number of ancestors explaining 70\% (10) and 50\% (5) of the genetic variability are quite similar (13 and 6, respectively for Andalusian), the lack of difference between $\mathrm{f}_{e}$ (13.3) and $f_{a}$ (13.1) showed that, based on pedigree, no significant bottleneck had occurred. $\mathrm{N}_{\mathrm{g}}$ was low due to the high probability of gene loss in the last generation, as a result of few descendants (the number of births has been globally declining since 1997), and the repeated use of the same individuals for breeding.

Parameters computed from the results of DNA analysis proved to be similar to those calculated for other breeds, especially for bottlenecked and small-sized populations. On a whole, these parameters showed higher or similar values than those obtained by Avdi and Banos (2008), consistent with the fact that we studied the entire Skyros pony population, instead of just one herd. MNA (5.93) was lower than that presented by Rognon et al. (2005) for seven

Table 5 - Genetic distance (Da) among the four Greek horse breeds based on blood group and biochemical loci and microsatellite loci.

\begin{tabular}{lcccc}
\hline & CH & PS & SK & PP \\
\hline CH & - & & & \\
PS & 0.062 & - & & \\
SK & 0.139 & 0.130 & - & \\
PP & 0.092 & 0.061 & 0.144 & - \\
\hline
\end{tabular}

Crete Horse (CH), Pinias Horse (PS), Skyros Pony (SK), Pindos Pony (PP). 
French horse breeds, where the lowest value was for the Comtois (6.36). Nevertheless, Ae (3.22) was within the range of reported values, i.e., from 3.05 for the Breton to 3.94 for the Selle Français. As with the Skyros pony, both the Comtois and Breton are local breeds. Thus, the value obtained for Skyros ponies was among the lowest observed, which is easily explained by the very limited size of the population (genetic drift effect). A number of studies have reported similar values for $\mathrm{He}$ and $\mathrm{Ho}$ in horse breeds, based upon microsatellite loci (Cañon et al., 2000; Curik et al., 2003; Aberle et al., 2004; Juras and Cothran, 2004; Gupta et al., 2005; Rognon et al., 2005; Luis et al., 2007). The number of loci tested ranged from 11 (Rognon et al., 2005 ) to 30 (Aberle et al., 2004). As there was no instance of exactly the same set of loci as ours being employed, a direct comparison becomes impossible, although these results are nevertheless useful for a better understanding of variation in the Skyros. The value of $\mathrm{He}(0.621)$ for the Skyros horse was well within the range for domestic horses, as a whole, although it was at the lower end of the range. The lowest values, viz. 0.442 for the Friesian (Juras and Cothran, 2004), 0.506 for the Sorraia and 0.609 for the Exmoor (Luis et al., 2007), were all from breeds with either small population-size or recent bottlenecks. The same pattern was seen for Ho. Thus, levels of heterozygosity in the Skyros breed are most like those observed in horse breeds with small population size that have undergone bottlenecks and inbreeding in recent times, which is consistent with the recent history of the Skyros horse. Actually, it is known that the population size has decreased, as confirmed by bottleneck-analysis of two of the three sub-populations. Nevertheless, no bottleneck signature was detected by testing in the population present on Skyros, even though the probability is high that this population has undergone outstanding reduction of late. There are five possible explanations (Luikart et al., 1998): 1) although a bottleneck occurred in the past, possibly more than 12 to 15 generations ago, it did not constitute an immediate and permanent bottleneck in population size (Luikart and Cornuet, 1998). 2) the bottleneck was too small to be detectable (Luikart et al., 1998). 3) either insufficient polymorphic loci were sampled to acquire the required statistical power for detecting the bottleneck, or the individuals sampled were not representative of the bottlenecked population itself. 4) a demographic, and not a genetic bottleneck, occurred. 5) the bottlenecked population was incompletely isolated, and so, genes obtained from immigrants (e.g., rare alleles) obscured subsequent genetic effects. In this case, these immigrant genes could have originated from the white horses present on the island, and which had been introduced more recently than the original pony. Hypothesis 1, 3 and 5 were, in this case, the most plausible explanations, with preference for the first, since 12-15 generations ago falls into the time of the foundation of modern horse breeds. However, no sufficient informa- tion was available to choose or definitely exclude either one or the other of these assumptions.

However, the relatively high level of heterozygosity and PIC values was comparable to those found in the Marwari horse population. This reflected high residual genetic variability that could be exploited for planning breeding strategies and giving precedence to this breed for conservation measures (Gupta et al., 2005).

As to the relationship between the Skyros pony and other Greek horse breeds, this study confirmed the conclusions by Apostolidis et al. (2001), regarding the former. Levels of genetic variability among Greek horse breeds, in general, were all within the range seen for other domestic horses. Values for Ho of biochemical loci varied widely, with the lowest $(0.307)$ found in the Pinias breed, a farm horse encountered in mountainous regions. This breed is relatively numerous, with a census population in Greece of about 5,000. The highest Ho was found in the Skyros pony from the island of the same name. As the census numbers of this small horse are less than 200, this high Ho was unexpected. Nevertheless, the $\mathrm{Ho}$ for microsatellites in this breed was the lowest in the four Greek breeds studied, and was even lower than the mean value for domestic breeds, as a whole. In general, there was no clear pattern of genetic variation associated with population size or degree of geographic isolation. This is most likely due to historical factors, such as how recently changes in population numbers took place or undocumented cross-breeding. Furthermore, individual genetic variation at biochemical loci does not correlate well with that at microsatellite loci. Variability at microsatellite loci is largely affected by the number of alleles, and, based upon demography, may change more rapidly than that at protein loci (Luis et al., 2007). In the Crete horse, another island population, the opposite pattern of variation is the case, with relatively low values for protein loci but relatively high variation at microsatellite loci.

In a comparison with other domestic breeds, using blood group and biochemical data (Figure 3), the Crete, Pindos and Pinias breeds revealed the highest affinity to Oriental types, especially those from the Middle East. This is probably a reflection of the possible Eastern origin of their ancestry. The Skyros pony clusters with two breeds with no clear mutual relationship or geographical closeness (Figure 3). These, two Zemaituki breeds, are Lithuanian horses, possibly of fairly ancient regional types, that show no clear relationship to any other breed tested up to that moment (Juras et al., 2003). The association of these with the Skyros, is most likely an artefact of the breeds tested, as well as the low level of breed diversity. Microsatellite and combined data (not shown) indicated that the Skyros has no close resemblance to any of the domestic breeds that were examined. This may be due, either to the low variability of the breed (Cothran and Luis, 2005), or to the true origins of the Skyros pony, tracing back to horse types not examined in this study. 


\section{Conclusion}

This study confirmed both the distinctiveness of the Skyros pony compared to the other Greek horse breeds, and the inexistence of a clear relationship with any other domestic breed. As genetic variability parameters showed similarities with bottlenecked and small-sized populations, the conclusion is that, probably, as a result of bottlenecks in two of the three subpopulations, a loss of this variability had already occurred within the Skyros horse population before the start of birth registration. However, further analysis, for example with SNP data, should be undertaken in order to prove this. At this moment, an effort by breeders to avoid mating between relatives would be helpful in reducing the rate of loss in genetic variability at the population level, as a means of conserving the relatively high genetic variability of the population, while genealogical parameters measuring pedigree depth (number of generation equivalents) continue to improve (Royo et al., 2007).

\section{Acknowledgments}

The first author, an F.R.I.A Fellow, acknowledges this support. Nicolas Gengler who is Research Associate of the National Fund for Scientific Research (FNRS) also acknowledges support received. EGC wishes to thank Ms. P Turner who provided some Skyros samples and Mr. J. Patton who provide the samples from Crete. Dr. T. Alifakiotis, Dr. A. Apostolidis and Mr. E. Rizos, at the Aristotle University, provided help in obtaining Greek samples and in genotyping. The efforts of the personnel (especially P. Henney) of the Equine Parentage Testing and Research Lab. (Univ. of Kentucky) in genotyping, is gratefully acknowledged. Support for some aspects of this study was provided by the Greek Ministry of Agriculture to TA and the Univ. of Kentucky Albert and Lorraine Clay Fellowship Program to EGC.

\section{References}

Aberle KS, Hamann H, Drögemüller C and Distl O (2004) Genetic diversity in German draught horse breeds compared with a group of primitive, riding and wild horses by means of microsatellite DNA markers. Anim Genet 35:270-277.

Alifakiotis TA (2000) The Indigenous horse of Greece. Ministry of Agriculture, Athens, $38 \mathrm{pp}$.

Andersson L (1985) The estimation of blood group gene frequencies: A note on the allocation method. Anim Blood Groups Biochem Genet 16:1-7.

Apostolidis AP, Mamuris Z, Karkavelia E and Alifakiotis T (2001) Comparison of Greek breeds of horses using RAPD markers. J Anim Breed Genet 118:47-56.

Aranguren-Mendez J, Jordana J and Gomez M (2002) Genetic conservation of five endangered Spanish donkey breeds. J Anim Breed Genet 119:256-263.

Avdi M and Banos G (2008) Genetic diversity and inbreeding in the Greek Skyros horse. Livest Sci 114:362-365.

Boichard D (2002) PEDIG: A Fortran package for pedigree analysis suited for large populations. In: Proceedings of the 7th
World Congress on Genetics Applied to Livestock Production, INRA, Castanet-Tolosan, pp 38.

Boichard D, Maignel L and Verrier E (1997) The value of using probabilities of gene origin to measure genetic variability in a population. Genet Select Evol 29:5-23.

Bömcke E and Gengler N (2009) Combining microsatellite and pedigree data to estimate relationships among Skyros ponies. J Appl Genet 50:133-143.

Bradley DG, MacHugh DE, Cunningham P and Loftus RT (1996) Mitochondrial diversity and the origins of African and European cattle. Proc Natl Acad Sci USA 93:5131-5135.

Caballero A and Toro MA (2002) Analysis of genetic diversity for the management of conserved subdivided populations. Conserv Genet 3:289-299.

Cañon J, Checa ML, Carleos C, Vega-Pla JL, Vallejo M and Dunner S (2000). The genetic structure of Spanish Celtic horse breeds inferred from microsatellite data. Anim Genet 31:39-48.

Cavalli-Sforza LL and Edwards AWF (1967) Phylogenetic analysis: Models and estimation procedures. Am J Hum Genet 19:233-257.

Chevalet C and de Rochambeau H (1986) Variabilité génétique et contrôle des souches consanguines. Sci Tech Lab 11:251257.

Cornuet J-M and Luikart G (1996) Description and evaluation of two tests for detecting recent bottlenecks. Genetics 144:2001-2014.

Cothran EG and Long YG (1994) A new phenogroup in the horse $D$ system of red cell alloantigens found in the Caspian Pony. Anim Genet 25:49-50.

Cothran EG and Luis C (2005) Genetic distance as a tool in conservation of rare horse breeds. In: Bodo I, Alderson L and Langolis B (eds) Conservation Genetics of Endangered Horse Breeds. Wageningen Academic Publishers, Wageningen, pp 55-71.

Cothran EG, Santos SA, Mozza MCM, Lear TL and Sereno JRB (1998) Genetics of the Pantaneiro horse of the Pantanal region of Brazil. Genet Mol Biol 21:343-349.

Curik I, Zechner P, Sölkner J, Achmann R, Bodo I, Dovc P, Kavar T, Marti E and Brem G (2003) Inbreeding, microsatellite heterozygosity, and morphological traits in Lipizzan horses. J Hered 94:125-132.

Dieringer D and Schlötterer C (2002) Microsatellite analyser (MSA): A platform independent analysis tool for large microsatellite data sets. Mol Ecol Notes 3:167-169.

FAO (1998) Secondary Guidelines for Development of National Farm Animal Genetic Resources Management Plans. Management of Small Populations at Risk. Initiative for Domestic Animal Diversity. FAO, Rome, 215 pp.

Felsenstein J (1993) PHYLIP (Phylogeny Inference Package) v. 3.5c. Department of Genetics, University of Washington.

Flury C, Tapio M, Sonstegard T, Drogemuller C, Leeb T, Simianer H, Hanotte O and Rieder S (2010) Effective population size of an indigenous Swiss cattle breed estimated from linkage disequilibrium. J Anim Breed Genet 127:339-347.

Guo SW and Thompson EA (1992) Performing the exact test of Hardy-Weinberg proportions for multiple alleles. Biometrics 48:361-372.

Glowatzki-Mullis ML, Muntwyler J, Pfister W, Marti E, Rieder S, Poncet PA and Gaillard C (2005) Genetic diversity among 
horse populations with a special focus on the FranchesMontagnes breed. Anim Genet 37:33-39.

Gupta AK, Chauhan M and Tandon SN (2005) Genetic diversity and bottleneck studies in the Marwari horse breed. J Genet 84:295-301.

Juras R and Cothran EG (2004) Microsatellites in Lithuanian native horse breeds: Usefulness for parentage testing. Biologija 4:6-9.

Juras R, Cothran EG and Klimas R (2003) Genetic analysis of three Lithuanian native horse breeds. Acta Agric Scand A 53:180-185.

Kimura M and Crow JF (1964) The number of alleles that can be maintained in a finite population. Genetics 49:725-738.

Lacy RC (1989) Analysis of founder representation in pedigrees: Founder equivalents and founder genome equivalents. Zoo Biol 8:111-123.

Luikart G and Cornuet JM (1998) Empirical evaluation of a test for identifying recently bottlenecked populations from allele frequency data. Conserv Biol 12:228-237.

Luikart G, Allendorf FW, Cornuet JM and Sherwin WB (1998) Distortion of allele frequency distributions provides a test for recent population bottleneck. J Hered 89:238-247.

Luis C, Juras R, Oom MM and Cothran EG (2007) Genetic diversity and relationships of Portuguese and other horse breeds based on protein and microsatellite loci variation. Anim Genet 38:20-27.

MacCluer JW, Van de Berg JL, Read B and Ryder OA (1986) Pedigree analysis by computer simulation. Zoo Biol 5:147160.

Maignel L, Boichard D and Verrier E (1996) Genetic variability of French dairy breeds estimated from pedigree information. Interbull Bull 14:49-54.

Moureaux S, Verrier E, Ricard A and Mériaux JC (1996) Genetic variability within French race and riding horse breeds from genealogical data and blood marker polymorphism. Genet Select Evol 28:83-102.

Nei M (1987) Molecular Evolutionary Genetics. Columbia University Press, New-York, 512 pp.

Ohta T and Kimura M (1973) A model of mutation appropriate to estimate the number of electrophoretically detectable alleles in a finite population. Genet Res 22:201-204.

Page RDM (1996) TREEVIEW: An application to display phylogenetic trees on personal computers. Cabios 12:357-358.

Piry S, Luikart G and Cornuet JM (1999) Bottleneck: A computer program for detecting recent reductions in the effective population size using allele frequency data. J Hered 90:502-503.
Raymond M and Rousset F (1995) GENEPOP v. 1.2: Population genetics software for exact tests and ecumenicism. J Hered $86: 248-249$.

Rochambeau $\mathrm{H}$ de, Fournet-Hanocq $\mathrm{F}$ and $\mathrm{Vu}$ Tien Khang $\mathrm{J}$ (2000) Measuring and managing genetic variability in small populations. Ann Zootech 49:77-93.

Rognon X, Mériaux JC and Verrier E (2005) Caractérisation génétique des races à l'aide des marqueurs moléculaires. In: 31éme Journée de la Recherche Equine, Haras Nationaux, pp 147-160.

Royo LJ, Alvarez I, Guttiérez JP, Fernández I and Goyache F (2007) Genetic variability in the endangered Asturcón pony assessed using genealogical and molecular information. Livest Sci 107:162-169.

Sandberg K and Cothran EG (2000) Biochemical genetics and blood groups. In: Bowling AT and Ruvinsky A (eds) The Genetics of The Horse. CABI Publishing, Wallingford, pp 85-108.

Solis A, Jugo BM, Mériaux JC, Iriondo M, Mazón LI, Aguirre AI, Vicario A and Estomba A (2005) Genetic diversity within and among four south European native horse breeds based on microsatellite DNA analysis: Implications for conservation. J Hered 96:670-678.

Strom H and Philipsson J (1978) Relative importance of performance tests in horse breeding. Livest Prod Sci 5:303-312.

Takezaki N and Nei M (1996) Genetic distance and reconstruction of phylogenetic trees from microsatellite DNA. Genetics 144:389-399.

Valera M, Molina A, Gutiérrez JP, Gómez J and Goyache F (2005) Pedigree analysis in the Andalusian horse: Population structure, genetic variability and influence of the Carthusian strain. Livest Prod Sci 95:57-66.

VanRaden PM (2008) Efficient methods to compute genomic predictions. J Dairy Sci 91:4414-4423.

Vogelstein B and Gillespie D (1979) Preparative and analytical purification of DNA from agarose. Proc Natl Acad Sci USA 76:615-619.

Zafrakas A (1991) The Equine and Its Feeding. Kyriakidis, Thessaloniki, 200 pp (in Greek).

\section{Internet Resources}

DAD-IS (2007) Domestic Animal Diversity Information System (DAD-IS), Food and Agriculture Organization of the United Nation, http://www.fao.org/dad-is/ (September 25, 2008).

\section{Associate Editor: Bertram Brenig}

License information: This is an open-access article distributed under the terms of the Creative Commons Attribution License, which permits unrestricted use, distribution, and reproduction in any medium, provided the original work is properly cited. 